Asian J. Med. Biol. Res. 2020, 6 (3), 599-607; doi: 10.3329/ajmbr.v6i3.49814

\author{
Asian Journal of \\ Medical and Biological Research \\ ISSN 2411-4472 (Print) 2412-5571 (Online) \\ www.ebupress.com/journal/ajmbr
}

\title{
Article \\ Customer relationship management in a tertiary level hospital
}

Afsana Bilkis ${ }^{1}$, Khorshed Ali Miah ${ }^{2}$, Arifa Sultana ${ }^{3}$, Mst. Shahida Parvin ${ }^{4}$, China Rani Mittra ${ }^{5}$ and Ashees Kumar Saha ${ }^{6}$

${ }^{1}$ Senior Staff Nurse, Khulna Medical College Hospital, Khulna, Bangladesh

${ }^{2}$ Associate Professor, (NIPSOM), Mohakhali, Dhaka-1212, Bangladesh

${ }^{3}$ Senior Staff Nurse, National Institute of Cardiovascular Diseases (NICVD), Dhaka, Bangladesh

${ }^{4}$ Senior Staff Nurse, Dhaka Medical College Hospital, Dhaka, Bangladesh

${ }^{5}$ Senior Staff Nurse, Upazilla Health Complex, Abhaynagar, Jashore, Bangladesh

${ }^{6}$ Senior Staff Nurse, Upazilla Health Complex, Bhagha, Rajshahi, Bangladesh

*Corresponding author: Afsana Bilkis, Senior Staff Nurse, Khulna Medical College Hospital, Khulna, Bangladesh. Phone: +8801712223335; E-mail: afsanabilkismph@gmail.com

Received: 07 September 2020/Accepted: 26 September 2020/ Published: 30 September 2020

\begin{abstract}
This cross-sectional study was conducted at OPD of Khulna Medical College Hospital (KMCH). This study aimed to assess the status of Customer Relationship Management (CRM) in a tertiary level hospital in Khulna city from $1^{\text {st }}$ January to $31^{\text {st }}$ December 2016. Total 200 samples were included purposively. Among them 150 respondents were health care receivers and 50 participants were health care providers and interviewed with a pre-tested semi-structured questionnaire and a checklist was used to collect information regarding administrative facility, physical facility and utility services. Data were analyzed by using Statistical Package for Social Science version (SPSS) 22 and appropriate statistical tests were performed. Most (62.3\%) of the service receivers were satisfied about the doctors dealing in OPD. It was found that majority of service provider (82\%) had not knowledge about CRM and its objectives. Majority (82\%) of the service receiver came to hospital willingly and (47.3\%) of service receivers were spent less than one hours for getting total treatment.). Most $(40 \%)$ of service providers said that there were a lack of service provider, modern equipment and medication in the OPD and they recommended that enhanced manpower, modern equipment and adequate supply of medication. About half $49.3 \%$ of the service receivers suggested in manpower should be increased. Therefore, attempts could be taken to implement customer relationship management as a process for improving hospitals performance and improving communication between service providers and service receiver in hospitals.
\end{abstract}

Keywords: customer relationship management; customers; consumer; client; satisfaction; outpatient department

\section{Introduction}

Customer Relationship Management (CRM) is a business approach that integrates people, processes and technology to maximize the relations of an organization with all types of customers. The true value of CRM is to transform strategic operational processes and business functions in order to retain customers and increase customer loyalty. According to Koh and Tan (2005), Customer Relationship Management is a core strategy in managing interactions between commercial organizations and their customers. It is no less important in a healthcare context. Because patients are the key customers of hospitals and other healthcare settings". The term Patient Relationship Management (PRM) is used for systems in the organizations. With PRM, healthcare organization focus is set on determining and meeting patient needs (Siau, 2003).

Hospital is a highly complex socio-economic scientific organization which provides comprehensive health care to the society and acts as a referral centre. Hospital problems are multifarious. Sixty percent of hospital budget was spent on wage and salaries of the staffs (Salauddin, 1998). When people were helped and their working 
environments were understood, the quality of work improves (Barton et al., 1980). Management system in health care delivery was handicapped by various problems in the country.

These problems should properly be identified and necessary measures should be taken in consistence with the requirement. It is easier to evaluate the patient's satisfaction towards the service than to evaluate the quality of medical services that they receive. Therefore, a probe into patient satisfaction can provide an important tool to improve the quality of service. Patient satisfaction is a multi-dimensional healthcare issue affected by many factors. Healthcare quality affects patient satisfaction and results in positive influence on patient behavior such as confidence in hospital care.

Patient satisfaction and healthcare service quality can be increased by using a multi-disciplinary approach that combines patient inputs as well as expert judgment (Naidu, 2009). Value is not just the price of the service delivered or discounts offered. In fact, the patient's perceptions of values are based on a number of factors that include quality-of-service, ease-of-delivery without- hassles, speed, responsiveness, flexibility and service excellence. Hospital administration should endeavor to improve hospital productivity and reduce cost while improving or maintaining service quality at the same level.

Bangladesh has made significant improvement in health sector, which make it an example for other developing countries even though being a resource poor country. Over the last decades key health indicators such as life expectancy and coverage of immunization have improved notably, whilst infant mortality, maternal mortality and fertility rates have dropped significantly (Osaman, 2008). An effectively performing health system is essential in improving the population's health status, providing safeguard against health-related financial threat and enhancing the health sector's responsiveness to customer's needs. A health system consists of all organizations, people and actions, whose primary intent is to promote, restore or maintain health.

Bangladesh has made remarkable progress in some indicators of health such as controlling infant, maternal and under-five mortality. It had achieved a credible record of sustaining $90 \%$ plus vaccine coverage in routine EPI with NIDS (national immunizations days) since 1995 (WHO, 2008). Customer relationship management (CRM), which has over riding significance for any business, is no less significant for hospital services. Hospitals are the most important element in any healthcare delivery system. A hospital plays a major role in maintaining and restoring the health of the people.

Outpatient departments (OPDs) provide medical services to the ambulatory patients. Majority of the patients receive services from the OPD. So maximum importance must be given to serve the people with highest possible quality services in order to fulfill their needs and reduce their sufferings. The patient who comes to the tertiary level hospital with a great hope and aspiration expects that proper and appropriate care would be provided in the OPD because the hospital is bearing highly skilled professionals and sophisticated medical instruments. The patients are more specific in their demand and expectation with regard to their ailments. Better services cannot be ensured until and unless various problems of recipients and service providers are known beforehand.

Health care services play a fundamental role in public welfare. A patient relationship management (PRM) system, more commonly known as customer relationship management (CRM), can thus be justifiably adopted by a public hospital, and may be important to leverage patient satisfaction.

Out-patient services and CRM: Hospital management is incomplete without caring for the outpatient services. An out-patient service is one of the most important departments, which determine the hospital image, provide diagnostic, curative, preventive and rehabilitative services.

\section{Materials and Methods}

The present research had been undertaken with the objective to assess the "Customer relationship management in a tertiary level Hospital". For achieving the objective mentioned above, this study has been carried out systematically and followed the methodology mentioned below:

\subsection{Ethical consideration}

Prior to the commencement of this study ethical approval of the research protocol from the Institutional Review Board (IRB) of National Institute of Preventive and Social Medicine (NIPSOM) was taken.

\subsection{Study design}

The study was a descriptive type of cross sectional study.

\subsection{Study setting}

The study was conducted at the Khulna Medical college hospital in Bangladesh. 


\subsection{Study period}

The study was conducted for the one year during the period of January, 2016 to December, 2016.

\subsection{Study population}

Health care receiver who attended the OPD services of Khulna Medical College Hospital and Health care providers who worked in that hospital.

\subsection{Sampling technique}

Purposive sampling was used for data collection.

\subsection{Sample size}

Sample size was calculated through following formula. $\mathrm{n}=\mathrm{Z}^{2} \mathrm{pq} / \mathrm{d}^{2}$

From the above formula the estimated sample size was 384 .

\subsection{Inclusion criteria}

\section{Inclusion criteria for service receiver-}

- Taking treatment facility in Medical college hospital

- Willing to participate in the study

\section{Inclusion criteria for service provider-}

- Permanent employee of the institution irrespective of age, gender and religion

- Having work experience in the study place for more than six months

\subsection{Research tools}

Semi-structured interviewer administered questionnaire was developed to collect the data. The questionnaire was prepared by using the selected variables according to objectives. Completed questionnaires were checked by the supervisors before collecting the data and questionnaire were planned designed according to the objectives to get information of the different variables. The questionnaire was prepared in English then translates in bangle. The questionnaire was pretested in the 500 bedded general hospital Mukda. It was conducted in Bangla language after the questions were pretested and necessary modifications were made. This result not included in final thesis

For collection of data, both questionnaire and checklist were used. Separate questionnaire was used for health care providers and health care receivers.

Checklist was used to collect information regarding administrative facility, physical facility and utility services.

\subsection{Statistical analysis}

After completion of data collection, to maintain consistency, the data were checked and edited manually and verified before tabulation. Data were coded, entered and analyzed in a computer. The statistical analysis was conducted using SPSS version 22.

\section{Results and Discussion}

This cross-sectional study was conducted in a tertiary level hospital named Khulna Medical College Hospital, Khulna. The study was carried out among 150 health care receivers and 50 participants were health care providers of this hospital.

The demographic characteristics of the respondents are shown in Table 1. 
Asian J. Med. Biol. Res. 2020, 6 (3)

Table 1. Demographic characteristics of service receiver $(n=150)$ and service provider $(n=50)$.

\begin{tabular}{|c|c|c|}
\hline \multicolumn{3}{|c|}{ Information of the service receivers: } \\
\hline Age group & Frequency & Percent \\
\hline Below 10 Years & 11 & 7.3 \\
\hline 11-20 Years & 17 & 11.3 \\
\hline $21-30$ Years & 35 & 23.3 \\
\hline 31-40 Years & 32 & 21.3 \\
\hline 41- 50 Years & 23 & 15.3 \\
\hline 51-60 Years & 16 & 10.7 \\
\hline Above 60 Years & 16 & 10.7 \\
\hline Sex & Frequency & Percent \\
\hline Male & 80 & 53 \\
\hline Female & 70 & 47 \\
\hline Level of education & Frequency & Percent \\
\hline Primary level & 35 & 23.3 \\
\hline Junior school level & 36 & 24 \\
\hline Secondary level & 37 & 24.7 \\
\hline Above Secondary degree & 42 & 28 \\
\hline \multicolumn{3}{|l|}{ Occupation } \\
\hline Employee & 31 & 20.7 \\
\hline Student & 26 & 17.3 \\
\hline Housewife & 47 & 31.3 \\
\hline Rickshaw puller & 21 & 14 \\
\hline Others & 25 & 16.7 \\
\hline \multicolumn{3}{|l|}{ Family income } \\
\hline Below 10000 & 43 & 28.67 \\
\hline $10001-20000$ & 61 & 40.67 \\
\hline 20001-30000 & 26 & 17.33 \\
\hline $30001-40000$ & 11 & 7.33 \\
\hline Above 40000 & 9 & 6 \\
\hline \multicolumn{3}{|c|}{ Information of the Service providers: } \\
\hline Age group & Frequency & Percent \\
\hline Up to 25 Years & 8 & 16.0 \\
\hline $31-35$ Years & 6 & 12.0 \\
\hline $36-40$ Years & 13 & 26.0 \\
\hline 41-45 Years & 6 & 12.0 \\
\hline 46- 50 Years & 7 & 14.0 \\
\hline $51-55$ years & 7 & 14.0 \\
\hline More than 55 Years & 3 & 6.0 \\
\hline Sex & Frequency & Percent \\
\hline Male & 29 & 58 \\
\hline Female & 21 & 42 \\
\hline Level of education & Frequency & Percent \\
\hline Up to SSC & 24 & 48.0 \\
\hline HSC & 6 & 12.0 \\
\hline Graduation & 6 & 12.0 \\
\hline Post-Graduation & 14 & 28.0 \\
\hline \multicolumn{3}{|l|}{ Occupation } \\
\hline Doctor & 10 & 20 \\
\hline Nurse & 8 & 16 \\
\hline Pharmacist & 4 & 8 \\
\hline Office attendant & 13 & 26 \\
\hline Receptionist & 3 & 6 \\
\hline Ward boy & 10 & 20 \\
\hline Others & 2 & 4 \\
\hline
\end{tabular}


Table 1 showed that the highest value was $21-30$ years which was $23.3 \%$ of the total value. The lowest value was below 10 years which $7.3 \%$ of the total value and Mean age $\pm \mathrm{SD}=36.15 \pm 16.46$. Most of the service receivers were male which value $53 \%$ and rest of the service receivers was $47 \%$ female. The frequency of no formal education was 14 among the 150 receiver which was $9.3 \%$ of the total value. The frequency of primary level was 35 (23.3\%) of the total value. Junior school level was 36 (24\%). Secondary level was 37 representing $24.7 \%$ of the total value. Only $28 \%$ of the receiver completed the above Secondary degree. A sizeable number of the receivers $14 \%$ were rickshaw puller, followed by $20.7 \%$ who were employed in various trades, majority $31.3 \%$ of whom was professional house wife. Most of the receiver $17.3 \%$ was student. Another $16.7 \%$ receiver said that they were others profession. Monthly family income of the service receivers, the highest value was 10001-20000 taka which was $61(40.67 \%)$ receivers among 150 Receivers.

Service provides by age, the highest value was $36-40$ years which was $26 \%$ of the total value. The lowest value was more than 55 years which $6 \%$ of the total value and Mean age $\pm \mathrm{SD}=41.02 \pm 9.11$. From the 50 respondents, 29 representing 58\% were males and 21 respondents representing $42 \%$ were females with educational level from Junior School Certificate and SSC, 12\% obtaining Higher Secondary Certificate, with $12 \%$ obtaining the graduation and $28 \%$ complete the post-graduation degree. Within the respondents $20 \%$ were Doctor, followed by $16 \%$ were Nurse. Majority $26 \%$ of whom were professional Office attendant. Another $6 \%$ were receptionist, $8 \%$ were pharmacist, $20 \%$ were ward boy and $4 \%$ were others profession.

Table 2. Distribution of the service receivers according to whether come willingly in the hospital, demand for consulting with doctors, easy find to the OPD, quickly name registration and total time required for getting treatment $(n=150)$.

\begin{tabular}{|l|l|l|}
\hline Come willing in the hospital & Frequency & Percent \\
\hline Yes & 123 & 82.0 \\
\hline No & 27 & 18.0 \\
\hline Total & 150 & 100.0 \\
\hline demand for consulting with doctors & Frequency & Percent \\
\hline Yes & 104 & 69.3 \\
\hline No & 46 & 30.7 \\
\hline Total & 150 & 100.0 \\
\hline Easy find to OPD & Frequency & Percent \\
\hline Yes & 137 & 91.3 \\
\hline No & 13 & 8.7 \\
\hline Total & 150 & 100.0 \\
\hline Quickly name registration & Frequency & Percent \\
\hline Yes & 104 & 69.3 \\
\hline No & 46 & 30.7 \\
\hline Total & 150 & 100.0 \\
\hline Total time required for getting treatment & Frequency & Percent \\
\hline Less than 1 hour & 71 & 47.3 \\
\hline Between 1-2 hours & 47 & 31.3 \\
\hline Between 2-3 hours & 14 & 9.3 \\
\hline More than 3 hours & 18 & 12.6 \\
\hline & & \\
\hline
\end{tabular}

Table 2 shows that there were $82 \%$ of the respondent came to the hospital OPD willingly for the treatment of their illness and only $18 \%$ of the service receiver came to there by the advice of others. Among them 104 receivers get the doctor according to their demand and 46 patients didn't get the doctor according to their demand. $91.3 \%$ of service receivers said that they easy to find the OPD, $8.7 \%$ of the receivers said that they did not find the OPD easily and $69.3 \%$ of the receivers quickly registered their name and there were $30.7 \%$ of the service receivers did not quickly registered their name from the tick counter of OPD.

During data collection $71(47.3 \%)$ service receivers reported that they spent time less than 1 hour at the hospital for getting total health service, the $47(31.3 \%)$ receivers said they spent times between 1-2 hours at the hospital for getting total health services. The $9.3 \%$ service receivers who spent times between 2-3 hours for getting total health services, rest of $18(12.6 \%)$ receivers said that they spent times more than 3 hours for getting total health services. 
Table 3. Distribution of service receivers by their opinion regarding the doctor listen health problems carefully and given advice $(n=150)$.

\begin{tabular}{|c|c|c|c|}
\hline \multicolumn{2}{|c|}{ Doctor listen the problem carefully } & Frequency & Percent \\
\hline \multicolumn{2}{|l|}{ Yes } & 126 & 84.0 \\
\hline \multicolumn{2}{|l|}{ No } & 24 & 16.0 \\
\hline \multicolumn{2}{|l|}{ Total } & 150 & 100.0 \\
\hline \multicolumn{4}{|c|}{ Doctor given advice } \\
\hline \multirow{3}{*}{$\begin{array}{l}\text { Variables } \\
\begin{array}{l}\text { No advice, only giving } \\
\text { prescription }\end{array}\end{array}$} & Comments & Frequency & Percent \\
\hline & Yes & 108 & 72.0 \\
\hline & No & 42 & 28.0 \\
\hline \multirow[t]{2}{*}{ Give advice only } & Yes & 19 & 12.7 \\
\hline & No & 131 & 87.3 \\
\hline \multirow[t]{2}{*}{ Ask to collect drugs } & Yes & 45 & 30.0 \\
\hline & No & 105 & 70.0 \\
\hline \multirow[t]{2}{*}{ Advice for operation } & Yes & 17 & 11.3 \\
\hline & No & 133 & 88.7 \\
\hline \multirow[t]{2}{*}{ Advice for investigation } & Yes & 60 & 40.0 \\
\hline & No & 90 & 60.0 \\
\hline
\end{tabular}

Table 3 shows that there were $84 \%$ of the service receiver said that the doctor listen their problem carefully and there were $16 \%$ of the service receiver said that the doctor don't listen their problem carefully and different patient get different advice from the doctors. 108 patients take only prescription among 150, 19 patients give advice only among 150, 45 patients ask to collected drugs among 150, 17 patients take advice for operation among 150 and 60 patients take advice for investigation among 150.

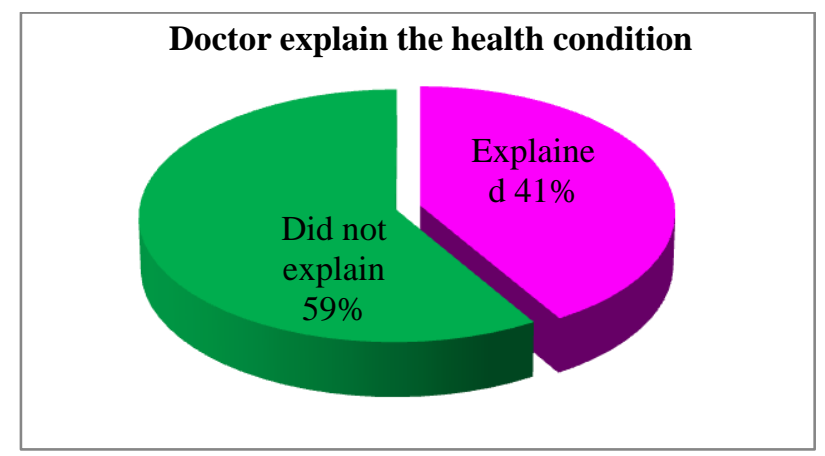

Figure 1. Distribution of service receivers by their opinion regarding the doctor explains their health condition. $(\mathbf{n}=150)$.

Figure 1 shows that there were $41 \%$ service receiver said that the doctor explain their health problem and $59 \%$ of the service receiver said that the doctor don't explain their health problem during the service receive.

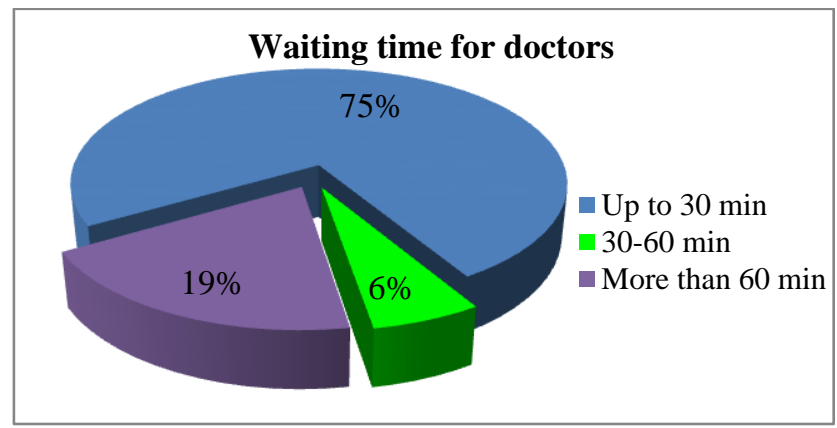

Figure 2. Distribution of the service receivers regarding to waiting time for doctors after arrival in hospital. $(\mathbf{n = 1 5 0})$. 
The above Figure 2 shows that the waiting time of the service receivers, there were $74.7 \%$ service receivers said that they wait up to 30 minutes for doctor and there were 6\% service receivers said that they wait 30-60 minutes for the doctors and $19.3 \%$ service receivers said that they wait more than 60 minutes for the doctors.

Table 4. Distribution of service receivers by their opinion regarding problem faced during receiving services and giving suggestion for improving more. $(n=150)$.

\begin{tabular}{|l|l|l|l|}
\hline Types of Opinion & Frequency & Percent & Rank \\
\hline Dissatisfaction to Physical facilities (Chair Fan) & 71 & 47.3 & 1 \\
\hline Decrease number of manpower & 55 & 36.7 & 2 \\
\hline Disturbance by broker & 53 & 35.3 & 3 \\
\hline Require long time & 47 & 31.3 & 4 \\
\hline Decrease medicine supply & 44 & 29.3 & 5 \\
\hline Poor security & 40 & 26.7 & 6 \\
\hline Unclean and unsatisfactory toilet facilities & 33 & 22.0 & 7 \\
\hline Interfere of medicine representative & 29 & 19.3 & 8 \\
\hline Dissatisfaction of investigation & 25 & 16.7 & 9 \\
\hline No provision of safe drinking water & 22 & 14.7 & 10 \\
\hline OPD Shifting & 21 & 14.0 & 11 \\
\hline Types of Suggestion & Frequency & Percent & Rank \\
\hline To increase manpower & 74 & 49.3 & 1 \\
\hline To increase modern seating arrangement & 61 & 40.7 & 2 \\
\hline To improve OPD security by RAB & 56 & 37.3 & 3 \\
\hline To improve Doctor patient relationship & 50 & 33.3 & 4 \\
\hline To increase medicine supply & 44 & 29.3 & 5 \\
\hline To establish modern investigation facilities & 39 & 26.0 & 6 \\
\hline Improve clean and satisfactory toilet facilities & 38 & 25.3 & 7 \\
\hline To open separate counter for staff & 37 & 24.7 & 8 \\
\hline To provide safe Drinking water & 30 & 20.0 & 9 \\
\hline To add evening shift & 28 & 18.7 & 10 \\
\hline
\end{tabular}

*Total value were exceed the sample size due to multiple variable

The above Table 4 shows that the opinion regarding the problem faced during receiving services, there were $47.3 \%$ of service receivers gave opinion about the dissatisfaction of physical facility, $36.7 \%$ were decrease number of manpower, $35.3 \%$ were disturbance by broker, $31.3 \%$ were require long time, $29.3 \%$ were decrease medicine supply, $26.7 \%$ were poor security. $22.0 \%$ were unclean and unsatisfactory toilet facilities, $19.3 \%$ were interfere of medicine representative, $16.7 \%$ were dissatisfaction of investigation, $14.7 \%$ were no provision of safe drinking water and rest of $14 \%$ service receivers gave opinion about OPD shifting.

Suggestion by the service receiver regarding services in tertiary level hospital for improving services. $49.3 \%$ of the service receivers suggested that manpower should be increase which rank was first (1). $40.7 \%$ of the service receivers suggested that seating arrangement should be modernized, $37.3 \%$ of service receivers suggested that improved the OPD security by involvement of $\mathrm{RAB}, 33.33 \%$ of service receivers suggested that improvement of the doctor patient relationship. Regarding the medicine supply $29.3 \%$ of the service receiver suggested that availability of medicine should be needed for better treatment. About the facility of hospital $26 \%$ service receivers suggested that establishes modern investigation facilities. Regarding cleanliness and hygiene practice $25.3 \%$ of the service receivers suggested that toilet should be clean for improve the satisfaction level. About the counter facility $24.7 \%$ of the service receivers suggested that counted should be separated for staff and patient. Drinking water facility $20 \%$ of the service receivers suggested that provide safe drinking water. Regarding the shifting $18.7 \%$ of the service receiver suggested that add the evening shifting which rank was last (10). 
Table 5. Distribution of service receivers by their opinion regarding dealing of service providers. $(\mathrm{n}=150)$.

\begin{tabular}{|l|l|l|l|l|l|l|}
\hline \multirow{2}{*}{ Service providers } & \multicolumn{6}{|c|}{ Opinion regarding dealing of service provider } \\
\cline { 2 - 7 } & $\begin{array}{l}\text { Highly } \\
\text { satisfied }\end{array}$ & Satisfied & Uncertain & Dissatisfied & $\begin{array}{l}\text { Highly } \\
\text { dissatisfied }\end{array}$ & Total \\
\hline \multirow{3}{*}{ Doctor } & 10 & 92 & 43 & 5 & 0 & 150 \\
& $(6.7 \%)$ & $(61.3 \%)$ & $(28.7 \%)$ & $(3.3 \%)$ & $(0 \%)$ & $(100 \%)$ \\
\hline \multirow{2}{*}{ Nurses } & 1 & 54 & 80 & 14 & 1 & 150 \\
Receptionist & $(0.7 \%)$ & $(36.0 \%)$ & $(53.3 \%)$ & $(9.3 \%)$ & $(0.7 \%)$ & $(100 \%)$ \\
\hline \multirow{2}{*}{ Pharmacy staffs } & 4 & 36 & 97 & 10 & 3 & 150 \\
& $(3.3 \%)$ & $(24.0 \%)$ & $(64.7 \%)$ & $(6.7 \%)$ & $(1.9 \%)$ & $(100 \%)$ \\
\hline \multirow{2}{*}{ Office attendants } & 3 & 46 & 94 & 7 & 0 & 150 \\
& $(2.0 \%)$ & $(30.7 \%)$ & $(62.7 \%)$ & $(4.7 \%)$ & $(0 \%)$ & $(100 \%)$ \\
\hline & $(0 \%)$ & 34 & 97 & 17 & 2 & 150 \\
& $(22.7 \%)$ & $(64.7 \%)$ & $(11.3 \%)$ & $(1.3 \%)$ & $(100 \%)$ \\
\hline
\end{tabular}

The table 5 shows opinion regarding dealing of service providers on level of satisfaction in OPD. Most (62.3\%) of the service receivers were satisfied about the doctors dealing in OPD while only 3.3\% of service receivers were dissatisfied regarding doctors dealing in OPD. About half (53.3\%) of the service receivers were uncertain regarding dealing of nurses while only $0.7 \%$ of service receivers were highly dissatisfied. On the other hand $24.0 \%$ of receivers were satisfied, $64.7 \%$ were uncertain while only $1.9 \%$ was highly dissatisfied regarding dealing of receptionist. Only $4.7 \%$ of service receivers were dissatisfied, $62.7 \%$ were uncertain and $30.7 \%$ of service receiver were satisfied regarding dealing of pharmacy staffs. Most $(64.7 \%)$ of service receivers were uncertain while $22.7 \%$ were satisfied and $11.3 \%$ of service receivers were dissatisfied regarding dealing office attendants in OPD.

Table 6. Distribution of service providers by their opinion regarding knowledge about their hospital OPD follows one of the objective of CRM and opinion about develop OPD Services $(n=50)$.

\begin{tabular}{|l|l|l|}
\hline Opinion & Frequency & Percentage \\
\hline Yes & 8 & 16 \\
\hline No & 1 & 2 \\
\hline Not applicable & 41 & 82 \\
\hline Total & 50 & 100 \\
\hline Opinion & \multicolumn{1}{|c|}{ Opinion about develop OPD services } & Percent \\
\hline Enhance manpower & Frequency & 10.0 \\
\hline $\begin{array}{l}\text { Develop cleaning facilities } \\
\text { Ensure enough emergency } \\
\text { medicine availability and Modern }\end{array}$ & 5 & 8.0 \\
\hline $\begin{array}{l}\text { Enhance manpower and } \\
\text { equipment }\end{array}$ & 1 & 2.0 \\
\hline $\begin{array}{l}\text { Enhance manpower modern } \\
\text { equipment and enough medicine } \\
\text { availability }\end{array}$ & 20 & 40.0 \\
\hline Total & 20 & 40.0 \\
\hline
\end{tabular}

To the question "Dose your hospital OPD follow one of the objective of PRM?" as shown in Table 6, there were 50 service providers, 8 representing $16 \%$ of the provide have gave their opinion that Hospital OPD actually follow one of the objective (Improving patient service) of PRM and 1 representing 2\% of the provider gave their opinion which hospital OPD does not follow any objective of CRM (PRM), and 41 (82\%) didn't have knowledge regarding about CRM objective.

Most (40\%) of the service providers gave their opinion to enhance manpower, modern equipment and enough medicine availability, $5 \%$ of the providers gave their opinion for the enhance manpower, $4 \%$ of the respondents gave their opinion to develop cleaning facility and only $2 \%$ of the respondents said that to ensure enough emergency medicine supply. 
In this study, all the service providers $(\mathrm{n}=50)$ said that there were no suggestion box in the OPD for the patient to give suggestion. Moreover, all the service providers $(n=50)$ suggested that they will give effective training on CRM because maximum service providers (51) have no knowledge about CRM.

\section{Conclusions and Recommendations}

The present study describes the customer relationship management in a tertiary level hospital' OPD of KMCH. It was found that majority of service provider had not knowledge about CRM and its objectives. Majority of the service receiver came to hospital willingly. Most of service providers said that there were a lack of service provider, modern equipment and medication in the OPD and they recommended that enhanced manpower, modern equipment and adequate supply of medication.

The following recommendations are put forward on behalf of researcher for further improvement of Customer Relationship Management in a Tertiary Level Hospital.

- Training should be given among the service provider regarding CRM

- There is health organization with wide size and scope in such a situation pre-planning should be ensured for a successful implementation of CRM.

- Electronic health record facility should be established.

- Suggestion box should be included in OPD in tertiary level hospital for improvement of services.

- Modernized investigation facility should be included.

- Hospital facility should be improve for customer satisfaction

- Periodical study focusing on CRM in the hospital should be implemented to keep up with the change of the phenomena.

\section{Conflict of interest}

None to declare

\section{References}

Barton E, R Mohon and M Piot, 1980. On being in charge.1st ed. Geneva World Health Organisation, pp 63.

Osaman FA, 2008. Health Policy Programmes and System in Bangladesh. Achievements and Challenges. South Asian Survey. pp. 263-288.

Koh HC and G Tan, 2005. Data mining applications in healthcare. Journal of Healthcare Information Management, 19: 64-72.

Siau K, 2003. "Health care informatics." IEEE transactions on information technology in biomedicine: a publication of the IEEE Engineering in Medicine and Biology Society, vol. 7, Mar. 2003, pp. 1-7.

Naidu A, 2009. Factors affecting patient satisfaction and healthcare quality. Int. J. Health Care Qual. Assur., 22: 366-381.

Salauddin AKM, 1998. Hospital management. 2nd ed. Published by Mrs Hosne Ara; July 1998. pp. 4-27. 